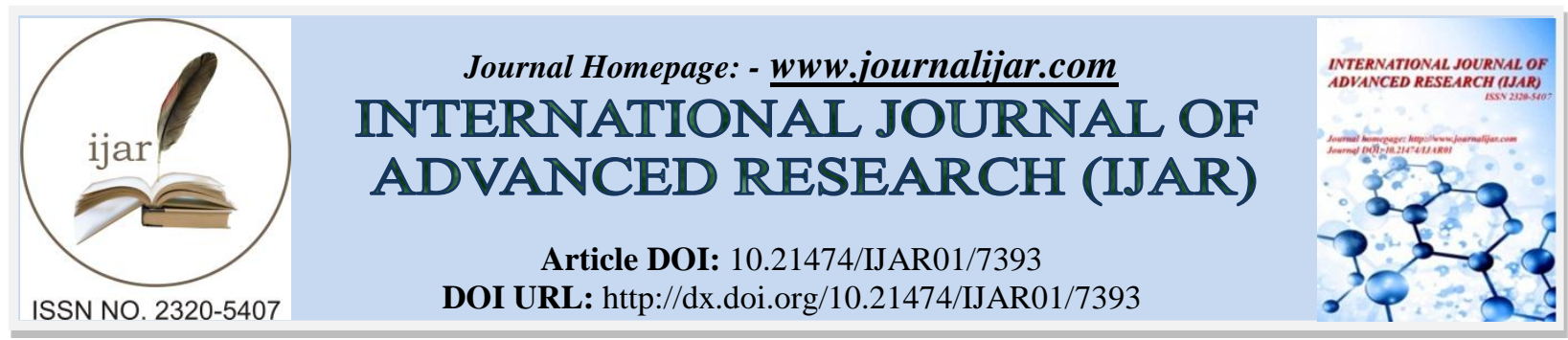

RESEARCH ARTICLE

\title{
A COMPARATIVE ANALYSIS OF THE PHILIPPINE NURSING CURRICULUM FROM OTHER COUNTRIES.
}

James Ryan Reblando.

St. Paul University- Manila.

\section{Manuscript Info}

Manuscript History

Received: 11 May 2018

Final Accepted: 13 June 2018

Published: July 2018

\begin{abstract}
The nursing practice is important in the healthcare industry. This paper is meant to analyze different nursing curriculums from different countries, their requirements and the core competencies they contribute to the practice. The introduction gives an overview of the nursing profession and introduces the key concepts of the paper. In the body an analysis of the Philippine, United States, Australian, United Kingdom and Middle East BSN curriculums is discussed. The sections include an introduction on the length of the curriculum followed by an extensive analysis of the core competencies and how they affect the nursing profession. Through a series of government and scholarly resources, the paper dwells into the essentials of BSN programs and how they influence the success of nurses in their professional lives. The conclusion outlines a summary of the paper.
\end{abstract}

Copy Right, IJAR, 2018, All rights reserved.

\section{Introduction:-}

A nurse is an important part of the healthcare system. They have the unique role of taking care of patients, assisting them through their recovery period by providing the necessary medications and emotional and physical support. Today the nursing is the most desired and innovative applied sciences. There has been a tremendous change in the profession over the past 50 years, which has changed the role of nurses in a hospital and the community. Traditionally nurses were untrained in medicine and their key roles included, dressing patients' wounds, feeding and bathing them and administering medication assigned by the doctor. In addition, it was primarily considered a woman's job. However as the importance of a nurse in a healthcare setting became more evident, changes needed to be made. Most of the changes included the creation of teaching curriculum for nurses and shifting patient care from a hospital-based system to a more community-based approach. In the training for nurses today, competence is a key learning outcome. A nurse has the responsibility to provide the appropriate care to a patient, following all the key nursing ethical standards and fulfill the mission statement of the institution they work for. In the nursing training programs, the roles of the nurse ha to be clearly outlined, together with common skills such as communication and organization which are secondary to the nurse's role but they remain a key component of patient care.

There is a global reduction in the quality of healthcare services. in the developing countries, poor working conditions, poor nursing curriculums, lack of equal pay and the availability of more lucrative options in the developed countries or private healthcare institutions leads to draining of healthcare personnel from government institutions (WHO, 2009). Nurses have to deal with increased workloads since most hospitals are underfunded and as such needed to hire less to cut their overall costs. When nurses are fired or resign their positions, the institution does not hire additional staff, instead of adding work to those remaining under their employment. Another problem

Corresponding Author:-James Ryan Reblando.

Address:-St. Paul University- Manila. 
is the lack of adequate training for most of the nurses in developing countries, which makes them incompetent for their jobs. Areas of nursing such as palliative care and care for children with chronic illness require special training and certain core competencies that will provide the nurse with the ability to care for the patients adequately (WHO, 2009). To combat these problems the developing countries have developed competency-based curriculums, which changes the nursing education process according to the global changes in the demands of the profession. These curriculums are based on the premise that the shifting trends in healthcare settings and global standards in the nursing practice need to be reflected in the training programs (WHO, 2009). The core competencies help to determine the excellence of a nurse, provide a competitive advantage for an institution and ensure that an organization enjoys long terms success.

There is a need to adjust the continuing education for nurses to keep at par with the transition, by widening the cope of nursing and actively promoting quality care delivery to those in need. In this regard, the paper reviews the current curriculum of the Philippine BSN, the core competencies and the change they have had on the overall nursing practice. Further, the paper carries out a comparative analysis of the nursing curriculum from the USA, Australia, UK, and the Middle East countries, and review how they comply with international standards. The primary goal of the paper is to show the differences in nursing curriculums between the developed and developing countries and outline recommendations which can be used to make the nursing practice more innovative and successful globally.

\section{Nursing Curriculum in the Philippines:-}

The Philippine curriculum in Nursing requires that a trainee complete a bachelor of science in nursing degree, which will be taken over a four-year period (Ilo.org, 2018). The Commission should recognize any institution offering the degree program on Higher education (Ched.gov, 2016). The BSN program is designed to offer a wholesome training experience, in which professional courses are taught with an emphasis on the nursing concepts, which are complemented by Related Learning Experiences (Ched.gov, 2016). The practicum program will focus on the nursing competencies and ensure that all the learning outcomes are achieved as the nurse graduates their course. The goal of the programs is to develop a professional nurse, who is able and capable of gaining entry-level position in a health facility (Ched.gov, 2016). The professional nurse graduating the program is expected to provide safe, quality and holistic care to different individuals with different age, gender and health-illness status, at-risk families and different population groups (Ched.gov, 2016). In addition, the nurse should actively collaborate with other professionals in the healthcare practice to promote strategies to improve health, prevent illness, alleviate suffering and provide end of life care.

The curriculum contains three major roles of a professional nurse. When a nurse graduates from the BSN program, they can perform the following roles; direct patient care, leadership and management and research (Ilo.org, 2018). A nurse can choose to major in, patient care focusing on different demographic groups, such as mothers and children, community groups, mental health patients and individuals with disabilities (Ched.gov, 2016). A nurse can also acquire the necessary leadership skills needed to lead service units and manage different programs in a healthcare facility (Lazarte, 2016). On the field of research, the nurse can carry out evidence-based research designed to determine the epidemiology of certain diseases, how to improve patient care and innovative designs of how the environment can be adjusted to improve patient outcomes both in a hospital and home setting. A graduate from the BSN program can pursue a career as an Advanced Practice Nurse, Nursing education specialist or a Nursing leadership and governance position (Ched.gov, 2016).

The program outcomes from the BSN incorporate a set of competencies which all the learners are expected to successfully demonstrate after completing the program. Some of the common standards include the ability to communicate well, both orally and written using both English and Filipino (Ilo.org, 2018). In addition, a graduate should be able to work effectively and independently in diverse teams. A professional nurse should also be able to act within the bounds of professional, social and ethical responsibilities (Ched.gov, 2016). The common standards specific to BSN include the ability to apply the knowledge of physical, social, natural and health sciences in the nursing practice (Ched.gov, 2016). A nurse is also expected to communicate effectively in speaking and writing using language that is culturally appropriate. Application of guidelines and principles of evidence-based practice when delivering care is also a common outcome of the BSN program.

Trainees within the program are also expected to work effectively in collaboration with multi-cultural and interdisciplinary teams, while also promoting the nursing standards following the existing legal, moral and ethical principles (Ched.gov, 2016). The BSN program also requires that a nurse provide safe and holistic care to 
individuals and their families using the appropriate nursing processes. An additional requirement is a need for the nurse to demonstrate management and leadership skills when delivering care for clients in a hospital setting. A nurse should also acquire the necessary research skills and collaborate with experienced researchers, to improve the practice and patient care standards (Ched.gov, 2016). A nurse should exhibit a passion for lifelong learning, and the desire to keep in touch with the trends in national and global developments in the healthcare system. Finally, the nurse should successfully apply technology in healthcare delivery while upholding the core values in the practice of the profession. Over the four-year period, outcomes are assessed at the end of each academic year. For the first year, students are expected to demonstrate basic nursing skills and gain the knowledge for rendering safe care in the nursing practice (Ched.gov, 2016). In the second year, the students are exposed to different situations involving mother and child or a family setting, in which they are expected to utilize the nursing process to provide holistic and appropriate care (Ched.gov, 2016). For the third year, the student gets to interact with community groups and examines the psychosocial health problems and maladaptive patterns of behavior in a variety of healthcare settings with the main goal being to show their ability to deliver quality care (Ched.gov, 2016). In the final year of the program, the nurse should display their leadership and management skills when dealing with the different groups of clients.

The Philippine BSN program identifies 11 core competency areas including; Safe and quality nursing care, quality improvement, record management, management of resources and environment, research, communication, health education, collaboration and teamwork, legal responsibilities, personal and professional development and ethical and moral responsibilities (Lazarte, 2016). For safe and quality nursing care there are 7 core competencies which require the nurse to exhibit the knowledge of the illness status of a patient, promote their safety and comfort, make sound decisions, setting care priorities based on the specific needs of the client, maintain continuous care and administer the right medication and assist in therapeutics according to the condition of the client (Lazarte, 2016). The nurse should also formulate a care plan, which should incorporate the patient, and other healthcare practitioners, implement the care plan to achieve desired patient outcomes, evaluate their progress and efficiently respond to the patient's condition. In the resources and environment management, there are five core competencies which require a nurse to organize their workload to enable efficient care while properly utilizing resources at their disposal to maintain the course of care for an individual (Lazarte, 2016). A nurse should ensure that the resources are functioning as they were planned for, constantly check the functioning of equipment and maintain an overall safe environment for the care of patients.

Core competencies for health education include the assessment of the learning needs of a patient, development of a health education plan derived from these needs, developing learning strategies for the education plan, implementation and evaluation of the outcomes of the education plan (Lazarte, 2016). Legal responsibility core competencies require that the nurse adheres to practices according to the nursing law and any other relevant legislation follow an organization's policies and procedures and document the care given to patients (Lazarte, 2016). Ethical and moral responsibilities core competencies compel the nurse to respect the rights of all clients, accept responsibility and accountability for all their decisions and work within the limits of the national and international code of ethics for nurses (Lazarte, 2016). The six core competencies for personal and professional development are identification of personal learning needs; actively pursuing continuing education; seeking involvement in professional organization and community based activities; maintaining a professional image of the nursing practice; upholding a positive attitude in the face of criticism and change and performing core functions according to the professional standards (Ched.gov, 2016).

For quality improvement, the nurse should gather appropriate data in order to improve overall quality of care; request and participate in performance audits; identify, reports any discrepancies or variations in the audit reports, and recommend a solution to the problems. Core competencies in research include gathering data using appropriate and internationally accepted methodologies; recommendation of actions for implementation of new strategies; analyzing and presenting results of their individual research and applying the results in the practice (Ched.gov, 2016). In records management, the three core competencies are the maintenance of accurate and updated records of patient care; regularly recording the outcomes of patient care and observe the legal obligations involved in the keeping of records.

The five communication core competencies are: establishment of a rapport with patients, their relatives and colleagues in the healthcare team; possessing the ability to identify and interpret verbal and nonverbal cues used in communication with patients; identification and utilization of the formal and informal communication models; 
responding to the unique needs of clients, their families and the whole community; and using appropriate technologies to enhance communication (Ched.gov, 2016). Finally, the collaboration and teamwork core competencies require that the nurse: establish a collaborative relationship with other members of a health team and initiate a collaborative care plan involving colleagues and other members in a healthcare team.

\section{Strengths of Compliance with International Standards:-}

The Philippine BSN curriculum is compliant with international standards of core competencies in the delivery of the program and the assessment methods. The core competencies identified in these areas are in line with the international standards for a nursing curriculum, which are used to identify the eligibility of a nurse for practice. The current curriculum provides the nurses with the essential skills required for a successful nurse and provides them with adequate training to make them better qualified for their careers (Lazarte, 2016). The program successfully provides nurses with adequate communication and leadership skills, which make them very capable of their jobs despite difficult circumstances in the health care system in the country.

\section{Weaknesses:-}

The main areas of weakness within the program are health education and research (Lazarte, 2016). The curriculum does not incorporate lessons on how nurses should educate the community on different aspects of healthcare. The curriculum does not also include training practicum on research, to provide students with the skills they need to carry out evidence-based research and promote the nursing practice. Nurses graduating from the program have problems identifying research gaps in the nursing practice and building new research on them to create better health practices in a community setting.

\section{The BSN Curriculum of the United States:-}

The course is completed in a 3-year period, where each year the students must attend mandatory clinical practice. The core competencies that are required for successful completion of a BSN program in the United States are classified into six groups:

Patient-centered care is focused on recognizing the client as the one with the control over his or her own care. The training program seeks to promote understanding of the dynamics of patient-centered care, such as the cultural, ethnic and social backgrounds and how they influence the patient (Tarzian \& ASBH Core Competencies Update Task, 2013). Further, examination of how safety and costs incurred in the delivery of care can be subsidized by incorporating patients in the decision-making processes. This incorporates identification of the barriers, which may prevent patients from actively utilizing healthcare processes (Tarzian \& ASBH Core Competencies Update Task, 2013). Exploration of the ethical and legal liabilities of patient care is key in the facilitation of informed consent for quality care (Qsen.org, 2018). The nurse should also be able to assess the communication skills involved in their encounters with patients and communicate the steps in each stage of the nursing process.

Core competencies in the teamwork and collaboration group are: description of individual strengths and limitation when functioning as part of a group; description of the scope of practice and recognizing the contribution of the team in assisting patients to achieve positive health outcomes; analyzing key discrepancies in the communication strategies and how they impact the functioning of the team; describing the team handles authority and how it affects patient care and safety; and identification of the system barriers which affect team functioning (Qsen.org, 2018).

For evidence-based practice, the key core competencies are knowledge of the basic scientific methods and principles; ability to differentiate between clinical opinions from evidence-based studies; examination of the role of evidence in the determination of good clinical practices; and discrimination between the rationales for modification of evidence-based practices (Qsen.org, 2018).

For quality improvement, the competencies are: describing strategies which will help to learn about the results of better care in a clinical setting; recognizing the role of nursing students in healthcare systems; identifying the importance of contrast and measurement in the assessment of healthcare quality and description of the approaches in changing care processes (Qsen.org, 2018).

For safety, the key competencies are: examination of the human factors associated with unsafe healthcare practices; describing factors that promote a safe culture in the workplace; identifying the processes involved in interpreting the origin of error and allocating accountability; and discussing the impact of resources associated with safety of 
patients and the potential impact of the initiatives and regulations (Tarzian \& ASBH Core Competencies Update Task, 2013).

For informatics, the key competencies are explaining why information technology is essential in patient care; identification of the information, which should be made available in databases used to support patient care; and using IT to monitor the source of different patient results (Qsen.org, 2018).

\section{BSN Program in Australia:-}

The program is completed in a 3-year period, where the student has to complete 48 units (Vu.edu.au, 2018). A training nurse is expected to complete over 1000 hours of supervised clinical practice, where they train under different clinical settings (Vu.edu.au, 2018). These clinical practice programs are designed to test the theoretical knowledge of the nurse and assist the development of the clinical skills in a real-life setting. The clinical practice begins from the first semester of enrollment and the hours are adjusted over the course depending on the needs of the curriculum (Vu.edu.au, 2018). Once a trainee completes the BSN program the Australian Nursing and Midwifery Accreditation Council, to acquire a practicing license (Nursingmidwiferyboardofaustralia.gov.au, 2018), must accredit them. There are seven standards of practice which is used to determine the success of the BSN curriculum: rational thinking in making critical nursing decisions; importance of professional and personal relationships in a healthcare setting; maintaining the physical and mental strength for the practice; frequent and exhaustive assessments; a nursing plan; sustaining a safe and responsible practice; and estimation of results which help to inform the nursing practice (Nursingmidwiferyboardofaustralia.gov.au, 2018). These standards are assessed at the end of each academic year to determine whether the nurse is qualified enough to function independently in a clinical setting and uphold the standards of care of the nursing practice.

The main difference with the Philippine nursing practice is the length of the curriculum. The Philippine curriculum takes four years while the Australian curriculum only takes three years. In addition, the key core competencies are determined in the school setting for the Philippine curriculum while in Australia the accreditation board is associated with the determination of eligibility of graduates from a recognized BSN program. In the Australian setting, a BSN degree gives career opportunities as a registered nurse or a general nursing practitioner (Vu.edu.au, 2018). Most of the graduates from the BSN program in the Philippines begin their careers as advanced practice nurses or education specialists. In addition, there is no single accreditation board in the Philippines, which determines the fate of nurses who have completed the BSN program. The national nursing examinations in the country are used to provide accreditation to the nurses, as long as they prove to exhibit all the core competencies required for successful nursing.

\section{BSN Program in the United Kingdom:-}

The BSN program is completed within three years (Nmc.org, 2010). During each semester, the students complete a nursing practice practicum session, which they use to develop interpersonal skills and gain the necessary practical skills needed in a clinical setting. The BSN curriculum in the United Kingdom is focused on demonstrating key competencies in four key areas; the professional values; teamwork and management; decision making in the nursing practice and interpersonal skills (Nmc.org, 2010).

The core competencies exhibited through professional values must include the ability of the nurse to practice with confidence abiding by the code of professional standards of practice and ethics, and support and promote health and well-being of people from different backgrounds (Nmc.org, 2010). The nurse must practice holistic, nonjudgmental holistic care, which avoids discrimination respects the individual choices of a patient and acknowledges diversity. The nurse should recognize their roles and responsibilities as well as those of other healthcare practitioners in a clinical setting (Nmc.org, 2010). The nurse should also recognize the limits of their abilities and seek help from professionals whenever necessary. In this regard, the nurse should learn to appreciate the significance of evidence in nursing and be accountable for all decisions they make concerning patient care.

Core competencies in leadership and management incorporate the ability of the nurse to systematically evaluate care to ensure that it helps patients achieve positive outcomes. The nurse should be aware of his or her own personality and beliefs and the impact they have in the delivery of care (Nmc.org, 2010). All nurses must work on their own as efficiently as they would in a team setting, across professional boundaries and respect the contributions of others in patient-centered care (Nmc.org, 2010). They should identify priorities in patient care and manage time and resources properly to uphold the level of care. 
In nursing practice and decision-making, the key competencies require nurses to demonstrate a comprehensive understanding of the human body and theoretical knowledge related to the physical, mental and psychological nature of the patient (Nmc.org, 2010). A nurse must keep in touch with the trends of changing knowledge in delivering quality care and constantly review evidence on best health practices (Nmc.org, 2010). They should demonstrate a unique understanding of the principles of public health, which will help them to respond better to health determinants and assess the needs of different groups of people (Nmc.org, 2010). Safety is important when assessing the correct use and limitations of common nursing interventions, for which the nurse should be able to evaluate and report any worries about the possible outcomes of the interventions (Nmc.org, 2010). Auditing of care on a regular basis is essential to help nurses improve clinical decision making, patient outcomes and make it easier to communicate changes to other stakeholders in the practice (Nmc.org, 2010).

Communication and interpersonal skills require that the nurse practice effective, compassionate and safe communication with a patient and their colleagues (Nmc.org, 2010). The core competencies stipulate that the nurse must use different communication techniques and technologies to support person-centered care and in the process contribute to the promotion of quality and safety (Nmc.org, 2010). The nurse is expected to have knowledge of verbal, nonverbal and written communication methods, which make it possible to interpret the needs of a patient. The nurse should actively participate in educating patients on the benefits of health-promoting behaviors through effective communication (Nmc.org, 2010). The nurses should respect the individual rights to confidentiality for a patient in accordance with the legal and ethical frameworks.

BSN programs in the Middle East:-

In the Middle East, BSN programs are taken over a four-year period. Once a BSN program is complete, a nurse has to seek accreditation through the national accreditation board (Healthcarestudies.com, 2018). Most students in the BSN program are female because of the nature of gender roles and discrimination in the region. The female graduates have to undergo a thorough assessment process to determine their eligibility for professional practice.

The learning outcomes of this curriculum include promoting, protecting and preserving the health of individuals and families and groups of people based on their individual characteristics (Healthcarestudies.com, 2018). The students should possess a high amount of theoretical knowledge and skills with the appropriate ethical attitude to provide adequate nursing care in a clinical setting (Healthcarestudies.com, 2018). The student should also develop an analytical, critical thinking and participation in the earning process through the acquired theoretical knowledge in the daily healthcare processes (Healthcarestudies.com, 2018). The student should seek to constantly upgrade the nursing practice through evidence-based research in order to keep in line with the latest scientific developments.

\section{Conclusion:-}

The BSN program in different countries is expected to conform to the international standards and follow a set of key core competencies required to uphold the quality and integrity of the practice. The Philippine BSN program is well within the limitations of the international standards but due to the economic nature of the country, they have not been able to fully invest in the curriculum. There are key areas of health education and research, which have not yet been fully integrated into the curriculum, but with the changing global standards, change is inevitable. In the United States, the healthcare curriculum is more developed and BSN graduates get to fulfill the core competencies of the program. The Australian program is more consolidated within the confines of the Nursing and Midwifery Board of Australia, as students are expected to conform to their standards of practice. The United Kingdom follows a similar system to the United States but with a different set of learning outcomes and core competencies. In the Middle East, the curriculum is designed to conform to the international standards, but the cultural and religious views of the country affect the core competencies of the BSN program. Generally, the core competencies and curriculum in these regions have similar outcomes, producing highly skilled nurses with good communication skills, adequate theoretical and practical knowledge which has contributed to the global advancement of the nursing practice. 


\section{References:-}

1. Ched.gov. (2016). POLICIES, STANDARDS AND GUIDELINES FOR THE BACHELOR OF SCIENCE IN NURSING. Retrieved from http://ched.gov.ph/wp-content/uploads/2017/11/Proposed-PSG-for-BS-NursingEducation.pdf

2. Healthcarestudies.com. (2018). Bachelor of Science in Nursing, Nicosia, Cyprus 2018. Retrieved from https://www.healthcarestudies.com/Bachelor-of-Science-in-Nursing/Cyprus/European-University-Cyprus/

3. Ilo.org. (2018). National Nursing Core Competency Standards. Retrieved from http://www.ilo.org/wcmsp5/groups/public/---asia/---ro-bangkok/---ilomanila/documents/publication/wcms_316218.pdf

4. Lazarte, F. (2016). Core Competencies of Beginning Staff Nurses: A Basis for Staff Development Training Program. Journal of Advanced Management Science, 4(2), 98-105. DOI: 10.12720/joams.4.2.98-105

5. Nmc.org. (2010). Standards of competence for registered nurses. Retrieved from https://www.nmc.org.uk/globalassets/sitedocuments/standards/nmc-standards-for-competence-for-registerednurses.pdf

6. Nursingmidwiferyboardofaustralia.gov.au. (2018). Nursing and Midwifery Board of Australia - Professional standards. Retrieved from http://www.nursingmidwiferyboard.gov.au/Codes-GuidelinesStatements/Professional-standards.aspx

7. Qsen.org. (2018). QSEN Competencies. Retrieved from http://qsen.org/competencies/pre-licensure-ksas/

8. Tarzian, A., \& ASBH Core Competencies Update Task. (2013). Health Care Ethics Consultation: An Update on Core Competencies and Emerging Standards from the American Society for Bioethics and Humanities' Core Competencies Update Task Force. The American Journal of Bioethics, 13(2), 3-13. DOI: 10.1080/15265161.2012.750388 (254792172228) WA.

9. Vu.edu.au. (2018). Bachelor of Nursing | Victoria University | Melbourne Australia. Retrieved from https://www.vu.edu.au/courses/bachelor-of-nursing-hbnb

10. WHO. (2009). Global standards for the initial education of professional nurses and midwives. Retrieved from http://www.who.int/hrh/nursing_midwifery/hrh_global_standards_education.pdf. 